\title{
An Investigation of the Faculty Members' Practice Excitement Styles During Distance Learning
}

\author{
Nusaiba A. Almousa ${ }^{1 *}$, Jehad A. Almomani ${ }^{2}$, Mo'en S. Alnasraween ${ }^{3}$ \\ ${ }^{1-3}$ Faculty of Education and Psychology, Amman Arab University, Amman, Jordan
}

\begin{abstract}
This study aimed to identify the degree to which faculty members practice excitement styles during distance learning. The study sample consisted of (298) randomly selected male and female students who enrolled in bachelor's and master's programs in various colleges at Amman Arab University, Jordan. To achieve the study's goal, the researchers followed the descriptive approach and developed a scale to reveal the degree to which faculty members' practice excitement styles during distance learning. After verifying its validity and reliability, it was applied to the study sample. The results showed that the degree to which faculty members practice excitement styles during distance learning was moderate with total arithmetic mean of (3.43), and the arithmetic means of the tool items ranged between (3.82-2.61). Also, there were no statistically significant differences in practicing excitement styles due to gender, faculty, and academic program variables.
\end{abstract}

Keywords: Distance learning, Excitement styles, Faculty members, University students.

\section{INTRODUCTION}

The e-learning community has grown as a result of huge breakthroughs in technology and current ways of communication around the world. There was a need to shed light on the teaching styles used in distant learning, especially during the corona pandemic (COVID19), because education is offered to learners at different times and places, and to meet the challenge of inspiring and attracting learners' attention in a remote context.

The teaching style is defined as "an identifiable set of classroom behaviors associated with and carried out by the instructor" (Biggs, J. B. (2001) p.76). It is represented by a set of procedures and skills practiced by teachers during the process of mutual interaction between them and learners and the various elements of the educational environment they prepare for the students, to provide them with knowledge, information, experiences, skills, and trends. To achieve this, the teacher must organize different educational situations to develop learners' ability to learn and practice learning to develop their personalities in all its aspects. There are various styles that the teacher can choose according to what suits the educational situation and the level of learners to achieve the desired goal. The quality of the learning style is determined by the extent of its compatibility with the educational purpose or objectives to be achieved, taking into account the learners' readiness, their interest in the learning subject, and directing them to effectively practice what they have learned inside and outside the educational situation (Lynch, 2016).

There has been an increase in interest in employing technology in various educational, administrative, and teaching processes. As a result, there was a need to increase interest in evaluating and developing the educational process to keep up with the demands of the 21 century and adapt to its variables, particularly the teaching styles used by teachers, since teachers play such an important role in the educational process; They are significant influencing elements in student accomplishment, progress, and motivation to learn. As a result, policymakers and education experts are looking for new approaches to improve teacher capacities and teaching styles. Distance education constitutes a noticeable change in the educational structure, methods, and styles; this type of education is concerned with using technological resources to make the learning process more flexible and attractive. The success of distance education depends on many factors, including the university's capabilities and infrastructure, the readiness of faculty members, and the extent to which they possess the competencies and skills necessary for this (Keller, Hoy, Goetz, \& Eva,2016; Sujit, Basak, Marguerite \& Be'langer, 2018).

Distance education is defined as "an educational system constructed on the delivery of educational materials to the learner through different technological means, where the learner is distant and separate from the teacher, and it is not mandatory to be in the same physical place during the learning process" (Sadeghi,2019, p. 80).

UNESCO (2002) has defined it as the education that focuses on open access to learning, provision of training,

Corresponding Author e-mail: nusaiba@aau.edu.jo https://orcid.org/0000-0001-8987-8036

How to cite this article: Almousa NA, Almomani JA, Alnasraween NS (2022). An Investigation of the Faculty Members'Practice Excitement Styles During Distance Learning. Pegem Journal of Education and Instruction, Vol. 12, No. 1, 2022, 31-38

Source of support: Nil

Conflict of interest: None.

DOI: $10.47750 /$ pegegog.12.01.04

Received: 19.09.2021

Accepted: 12.11.2021 Publication: 01.01.2022 
freeing learners from time and space constraints, and providing flexible learning opportunities for individuals and groups of learners using two-way communication.

In distant learning, the teaching style and excitement of the teacher provide a significant challenge. It has a critical role in drawing learners' attention and keeping them engaged throughout the educational process. As a result, it has an impact on student interaction. There are no specific guidelines that the teacher should follow during the teaching process because the teaching style is tied to the instructor's qualities and personality traits. As a result, the nature of the teaching style is influenced by the teacher's personality, linguistic expressions, body language, facial and emotional expressions, voice tone and pronunciation, signs and gestures, value expressions, and so on. Finally, a teacher's teaching style represents the unique personality features that separate one teacher from another (Lazarides, Gaspard, and Dicke 2019).

Because of the distance education system, it is necessary to vary teaching styles to keep students interested and engaged in the learning process. As a result, special training should be provided to faculty members on how to use and employ interactive electronic applications and modern technological means to teach and interact with students through educational platforms available to them, to keep the excitement and motivate the learners. Teachers must also have an engaging and participatory teaching approach that incorporates communication, reasoning, illustration, and presenting examples.. (Frenzel, et all., 2019).

For the teacher's style to be exciting and engaging, the following must be considered:

- Knowing the needs of the learners and constantly working on exciting them (using a joke, thriller story, or motivational sentences) therefore they do not get distracted and bored. If they get bored, they will turn away, and the teacher will start talking to himself, especially in distance education.

- The style should be characterized by ease of expression and clarity of meaning (the simplicity and clarity of the used phrases) since understanding the meanings is the basis of the excitement style. Finally, the logical arrangement of the topic is interconnected and coherent, with no gaps in it, starting with the introductions, the presentation body, and the conclusion.

- The teacher's excitement for teaching and his ability to choose solid words and structures, short and easy-tounderstand sentences, and avoid extended expressions that bring boredom to the listener and lead to the loss of excitement during the learning process. The teacher must use various styles to achieve this, ranging from asking questions, answering, storytelling, wondering and employing imagination, and choosing words that provoke excitement and create images and ideas related to the topic.
- Changing the tone of voice, choosing appropriate phrases of praise, reducing direct criticism, and always focusing on recognition. Reinforce students whenever necessary, allow discussions between students themselves and focus on exciting, out-of-the-box questions.

- Motivating students and directing their interests. The teacher needs a particular effort to encourage the individual's activity, guide students' behavior, and arouse their attention, interests, and curiosity. For example, the teacher can start his educational activity with an exciting story or situation or poses a problem that challenges students' thinking and captures their interests. (Frenzel, Taxer, Schwab and Kuhbandner, 2019; HE, 2018).

Based on the above, it becomes clear to us the importance of practicing excitement styles in education to stimulate the learners, attracting their attention, and making the learning process an enjoyable long-lasting process. Thus, it contributes to maintaining learning impact for a long time and brings meaning closer to understanding. Also, it helps the learner developing his knowledge, information, experiences, skills, and attitudes, especially the rational scientific thinking process and the desire to seek knowledge with pleasure and joy. It contributes to creating a positive environment for education and maintaining mutual trust and respect between the teacher and his students.

\section{Study Questions and Research Problem}

Teaching is among the tasks that require a particular type of effort, as it deals with the human element and requires influence and continuous development to achieve its goals. Therefore, there is no one specific way that fits all, nor does it depend on a particular approach. Instead, it is mandatory to diversify teaching and learning styles to improve educational outcomes, excite and motivate students, and make the learning process more effective. Among the most prominent factors that may contribute to achieving success and excellence for teachers is their employment of the excitement styles in the educational process in a way that prompts the learner to interact with the teacher during the educational journey automatically and spontaneously.

Considering the Corona pandemic that swept the world in 2019, distance education has been activated mainly as an alternative to direct instruction in universities. Most universities today use learning management software and interactive electronic programs with the feature of (video conference) that allows the teacher and the learner to communicate and transmit voice and facial expressions, send feedback and promote quick electronic questions that inspire thinking and excitement. Thus, this study aimed to investigate the degree to which faculty members practice excitement styles during distance learning since excitement style is a critical factor that influences the learning process, especially with the physical distance challenge. 
This study aimed to answer two research questions;

- What is the degree to which faculty members practice excitement styles during distance learning from the students' perspective?

- Are there statistically significant differences at the level of $(\alpha=0.05)$ in the degree to which faculty members' practice excitement styles during distance learning due to (gender, academic program, and faculty) variables, from the students' perspective?

\section{Significance of the Study:}

The study tried to uncover the degree to which faculty members' practice excitement styles during distance learning. It provides feedback to faculty members to reveal the strengths and weaknesses in the degree to which they practice excitement styles in distance learning in Amman Arab University in particular and local and international universities in general. It is considered a unified approach to studying the distance education system in universities. Also, it contributes to providing information to decision-makers in higher education institutions to shed light on it and overcome its shortcomings. It can be an appropriate psychometric tool that contributes to strengthening the theoretical framework and providing feedback to higher education institutions and faculty members about their practice for excitement styles.

\section{Study Objectives}

- The study aimed to uncover the degree to which faculty members practice different excitement styles during distance learning from the students' perspective.

- The degree to which faculty members deploy excitement styles during distance learning, as determined by characteristics such as gender, faculty, and scientific program.

\section{Procedural Definition}

The excitement style is the practical procedure that faculty members at Amman Arab University practice during distance university education to attract students' attention, achieve educational goals, and reduce boredom in the virtual classroom. To achieve the purpose of the study, the researchers created a scale that will measure the total scores the study sample got.

\section{Limitations and Delimitation of theStudy}

- This study was limited to bachelor's and master's level students of Amman Arab University in Jordan for the summer semester of the academic year 2019/ 2020.

- The results of this study are delimited by the validity \& reliability of the study tool.

\section{Literature Review}

Referring to previous studies, the researchers did not find similar studies related to the excitement styles during distance learning among faculty members in universities. Therefore, the previous studies included here relate to the excitement styles used in the education process in general. The most prominent ones are listed below:

- Al-Hudairis (2019) conducted a study to explore the different styles used by secondary school teachers and their relation to increasing the learner's motivation towards learning. The study sample - that followed the descriptive analytical approach- consisted of (70) teachers from secondary school for the first and second secondary grades, And (200) randomly selected students from the first and second secondary grades. After applying the two study tools and analyzing them, the results showed a relation between the styles used by the secondary school teacher and the increase in learner's motivation towards learning. There were statistically significant differences at the level $(\alpha 0.05)$ in the styles used by the secondary school teacher to increase the learner's motivation to learn due to the years of experience variable, and the absence of statistically significant differences at ( $\alpha$ 0.05) level attributed to the qualification variable

- In Al-Mahdi, Al-Hatami, and Al-Fawzi (2018), the study aimed to determine the role of using a computerized application in teaching to improve the student learning experience (the researcher followed the descriptive mixed method). The questionnaire was distributed to (166) male and female students from the University of Bahrain. The results showed improvement in student participation, saving learning time, ensuring equal participation opportunity, and creating a pleasant, exciting educational environment.

- Abu Daf (2015) followed the descriptive-analytical approach in conducting a study to reveal the styles of reinforcement and excitement as mentioned in prophet Muhammad Sunnah and the degree to which private secondary school teachers in Gaza city practice these styles. After applying the study tool (the questionnaire), the results showed that private secondary school teachers use reinforcement and excitement styles to a high degree. Furthermore, there is a statistically significant difference in practicing excitement styles due to training courses variable in favor of those who attended 2-4 training courses. The study also showed no significant difference due to Gender or special variables.

Jassim (2015) also conducted a study aimed at finding the degree to which Islamic education teachers practice excitement and enthusiasm styles in the upper elementary stage in teaching the Holy Qur'an from their perspective in Amman. The study 
tool was determined considering gender, qualification, and experience variables. The researcher followed the descriptive approach, and the study results showed that the Islamic education teachers' practice enthusiasm style came to a large extent in the first place, and the excitement styles ranked last. It also showed statistically significant differences in the degree to which Islamic education teachers practice excitement and enthusiasm styles due to gender variables and in favor of females and no statistically significant differences to the scientific qualification variable. Moreover, there are statistically significant differences among the same sample in the degree Islamic education teachers' practice enthusiasm styles in teaching higher elementary students in Amman due to the education experience variable in favor of the experience variable (10 years or more). At the same time, there are no significant differences due to the education experience variable in excitement.

- Another study conducted by Al-Jarrah, Al-Mafleh, Al-Rabee ', and Ghawanimah (2014) aimed to investigate the impact of using computers to improve motivation towards learning mathematics. For this purpose, educational software was designed through which students are taught multiplication, and the researchers created a measure to measure motivation towards learning. The study sample consisted of 43 students from the second grade distributed randomly into two groups. One was an experimental group who studied using educational software, and the other was a control who learned in the usual way. The results showed statistically significant differences at the level (a 0.05) in motivation to learn mathematics and in the dimensions of motivation to learn due to the teaching method in favor of the experimental group. There were no statistically significant differences due to gender or the interaction between gender and the teaching methods variable.

- Ghobari and Abu Shairah (2009) conducted a study to identify the degree of practicing curiosity stimulation strategies among secondary school teachers in Irbid governorate from the students' perspective. The results showed that teachers use strategies to stimulate curiosity to a moderate degree. In addition, they pay more attention to question-asking strategies, correction strategies, reinforcement strategies, and finally, the learning and exploration environment. The results also showed that students' opinions on the degree to which teachers practice curiosity stimulation strategies differ according to gender. Females see that teachers use curiosity stimulation strategies to a greater extent than males. Also, Students' opinions differ according to the type of school, as private school students see that teachers use strategies to stimulate curiosity to a greater extent than public school students. In contrast, opinions did not differ according to the high school streams.
- Previous studies show an evident agreement focusing on the degree to which faculty members and teachers practice different styles to achieve enthusiasm and excitement in the educational process in different academic stages, such as the study of both the Haders (2019) Al Mahdi and others (2018); Abu Daf (2015); Gbari and Abu Shairah (2009); Jasim (2015). Furthermore, there is a discrepancy between these studies in the degree of practicing these styles according to several variables such as the educational stage, gender, experience, and the education sector (government / private). Some other studies, such as the study of Al-Jarrah, Al-Mufleh, Al-Rabee ', and Ghawanimah (2014), have shown an effect of using computers in the education process on students motivation towards learning. However, the current study differed from the previous ones. It aimed to uncover the degree to which faculty members practice excitement styles during distance learning from the students' perspective in Amman Arab University. The literature shows no other studies focusing on the same aspect, which may be due to the recent focus on distance education globally, especially after the emergence of the Corona pandemic.

\section{Study Procedures and Methodology}

Study population: The study population consisted of (2110) students in Amman Arab University enrolled in master's and bachelor's programs in all faculties for the academic year (2019/2020). Table 1 shows the study community.

Study sample: The study sample consisted of (298) male and female students, with (14\%) of graduate and undergraduate students at Amman Arab University. The sample was chosen in the most accessible way possible by distributing an electronic link to university students.

\section{Study Tool}

First, the validity of the study tool (scale of excitement styles during university education)

- Validity of the content

Nine referees with expertise in measurement, evaluation, curricula, and teaching methods verified the scale's validity. The necessary amendments were made considering the comments received from the referees and the scale in its final form consisting of (24) items.

- Indicators of the validity of the structure

Structure validity indicators were verified by computing the Pearson correlation coefficient to examine the values of the correlation coefficients between the items and total score, as shown in Table 2.

Table (2) showed that the values of the correlation coefficients were higher than (0.30), which indicates that the scale has the validity of a suitable structure. 
Table1: Distribution of the study sample

\begin{tabular}{lll}
\hline Gender & $N$ & Percentage \\
\hline male & 116 & $39 \%$ \\
Femal & 182 & $61 \%$ \\
total & 298 & - \\
faculty & $\mathrm{N}$ & - \\
Humaniteran & 200 & $67 \%$ \\
scientif & 98 & $33 \%$ \\
Total & 298 & - \\
program & $\mathrm{N}$ & - \\
Baclories & 95 & $32 \%$ \\
High Studies & 203 & $68 \%$ \\
Total & 298 & \\
\hline
\end{tabular}

\section{Second: the Stability of the Study Tool}

The stability of the study tool was verified by finding the internal consistency using the Cronbach Alpha method, with a value of (0.86), which is suitable for the current study's purpose.

\section{Results AND DISCUSSION}

The Results of answering and discussing the first study question: What is the degree to which faculty members practice excitement styles in distance learning from the students' perspective?

The arithmetic means and standard deviations were extracted to the degree to which faculty members practice excitement styles in distance learning, as shown in Table 3.

Results of Table (3) shows the total arithmetic mean (3.43) with a moderate degree, and the arithmetic means of the tool items ranged between (3.82-2.61); item (1) states, "The teacher uses words of praise and encouragement, which excites the learners to participate" ranked first, with an arithmetic mean of (3.43) and with a standard deviation of (1). Item (9) states, "The teacher changes his tone of voice while speaking to gain attention" ranked last, with an arithmetic mean of (2.61) and standard deviation of (1.50) and with a moderate degree.

The researchers attribute the above result to teachers' awareness of the importance of employing excitement styles in developing students' confidence by actively participating in the educational process. Moreover, excitement adds benefit and joy to the educational process; it fulfills students' needs and satisfies their learning desire. It helps analyze students' readiness and excites and motivates learners to engage more where these styles allow teachers to recognize students' levels and ensure their active participation. It appears to be that teachers are already familiar with these styles as they use them in face-to-face education. The researchers suggest that Teachers' use of praise, good expression, repetition, and
Table 2: The values of correlation coefficients between items and the overall score

\begin{tabular}{llll}
\hline Item & $\begin{array}{l}\text { Correlation between } \\
\text { item and total score }\end{array}$ & Item & $\begin{array}{l}\text { Correlation between item } \\
\text { and total score }\end{array}$ \\
\hline $0.50^{* *}$ & 13. & $0.49^{\star}$ \\
$0.33^{*}$ & 14. & $0.60^{* *}$ \\
$0.61^{* *}$ & 15. & $0.54^{* *}$ \\
$0.52^{* *}$ & 16. & $0.70^{* *}$ \\
$0.56^{* *}$ & 17. & $0.36^{*}$ \\
$0.30^{*}$ & 18. & $0.35^{\star}$ \\
$0.57^{* *}$ & 19. & $0.34^{\star}$ \\
$0.50^{* *}$ & 20. & $0.33^{\star}$ \\
$0.33^{*}$ & 21. & $0.42^{\star}$ \\
$0.61^{* *}$ & 22. & $0.44^{\star}$ \\
$0.52^{* *}$ & 23. & $0.48^{\star}$ \\
$0.42^{*}$ & 24. & $0.53^{* *}$ \\
\hline
\end{tabular}

${ }^{* *} \operatorname{sig}(\alpha=0.01) * \operatorname{sig}(\alpha=0.05)$

balance between pleasure and value through the educational journey ranked the top since teachers use them in both proximate \& distance education. The above results are consistent with the philosophy that focuses on making the learner the center of the educational process

Also, the average score achieved by faculty members on the scale is referred to the educational and technological training faculty members received on how to employ technology, communication, and presentation tools in the educational process. This study is consistent with the study of Elmahdi, Al-Hattami \& Fawzi (2018), Jassim (2015), and Abu Daf (2015) on showing the importance of deploying excitement styles and enthusiasm during learning and its positive implications on the educational process.

- Results and discussion related to the second question: are there statistically significant differences at the level of $(\alpha=0.05)$ in the degree to which faculty members practice excitement styles during distance learning due to (gender, academic program, and faculty) variables from the students' perspective?

To find out the degree to which faculty members practice excitement styles during distance learning with different variables like student's gender, the academic program, and the faculty; The arithmetic means and standard deviations were extracted as shown in Table 4.

Table (4) shows a clear difference between the arithmetic means on the total score of the excitement styles scale attributed to the (gender, college, and program) variables related to the study individuals. Therefore, the analysis of multiple variances was extracted as shown in Table (5) to find if these differences are statistically significant.

Results of Table (5) show no significant differences due to gender, academic program, and faculty variables related 
Table 3: Arithmetic means and standard deviation for the degree to which faculty members practice excitement styles during university education from the students' perspective

\begin{tabular}{|c|c|c|c|c|c|}
\hline No & Item & Arithmetic Mean & Standard Deviation & Rank & Level \\
\hline 1 & $\begin{array}{l}\text { The teacher uses words of praise and encouragement, } \\
\text { which excites the learners to participate }\end{array}$ & 3.82 & 1.22 & 1 & High \\
\hline 12 & The teacher uses the poll technique to excite the students & 3.80 & 1.29 & 2 & High \\
\hline 19 & The teacher makes teaching enjoyable and useful & 3.80 & 1.23 & 3 & High \\
\hline 17 & The teacher provokes curiosity among students & 3.70 & 1.21 & 4 & High \\
\hline 20 & The teacher uses repetition, articulation, and clarification & 3.69 & 1.31 & 5 & High \\
\hline 4 & $\begin{array}{l}\text { The teacher uses the camera while communicating with } \\
\text { students }\end{array}$ & 3.63 & 1.27 & 6 & Moderate \\
\hline 22 & The teacher uses multiple electronic learning resources & 3.62 & 1.24 & 7 & Moderate \\
\hline 18 & $\begin{array}{l}\text { The teacher encourages his students to complete the } \\
\text { e-learning tasks successfully and helps them to achieve it }\end{array}$ & 3.59 & 1.32 & 8 & moderate \\
\hline 10 & $\begin{array}{l}\text { The teacher links the previous information with the new } \\
\text { topic }\end{array}$ & 3.55 & 1.27 & 9 & Moderate \\
\hline 6 & The teacher uses examples and stories & 3.54 & 1.32 & 10 & Moderate \\
\hline 2 & $\begin{array}{l}\text { The teacher uses a wide range of verbal communication } \\
\text { styles like questioning }\end{array}$ & 3.48 & 1.31 & 11 & Moderate \\
\hline 15 & $\begin{array}{l}\text { The teacher allows learners to participate, discuss, debate, } \\
\text { and ask question }\end{array}$ & 3.47 & 1.23 & 12 & Moderate \\
\hline 5 & $\begin{array}{l}\text { The teacher allows learners to take on the role of the } \\
\text { teacher and manage the educational situation }\end{array}$ & 3.45 & 1.23 & 13 & Moderate \\
\hline 23 & The teacher shows enthusiasm during the teaching process & 3.44 & 1.27 & 14 & Moderate \\
\hline 14 & the teacher uses fun and humor to avoid boredom & 3.41 & 1.23 & 15 & moderate \\
\hline 24 & The teacher uses various styles, so time passes quickly & 3.39 & 1.29 & 16 & Moderate \\
\hline 7 & $\begin{array}{l}\text { The teacher introduces discussion topics related to the } \\
\text { lecture }\end{array}$ & 3.36 & 1.30 & 17 & Moderate \\
\hline 16 & The teacher uses image-supported electronic tools & 3.36 & 1.40 & 18 & Moderate \\
\hline 3 & The teacher raises questions to excite and motivate learners & 3.31 & 1.36 & 19 & Moderate \\
\hline 8 & $\begin{array}{l}\text { The teacher uses various illustration tools, such as } \\
\text { drawings, videos, presentations, and others }\end{array}$ & 3.26 & 1.34 & 20 & Moderate \\
\hline 13 & $\begin{array}{l}\text { The teacher energies the learners every once and a while to } \\
\text { keep them involved and driven }\end{array}$ & 3.16 & 1.35 & 21 & Moderate \\
\hline 11 & The teacher uses different words for reinforcement & 3.03 & 1.30 & 22 & Moderate \\
\hline 21 & $\begin{array}{l}\text { The teacher uses student names appropriately during } \\
\text { instruction }\end{array}$ & 2.93 & 1.43 & 23 & Moderate \\
\hline \multirow[t]{2}{*}{9} & $\begin{array}{l}\text { The teacher changes his tonality while speaking to gain } \\
\text { attention }\end{array}$ & 2.61 & 1.50 & 24 & Moderate \\
\hline & Total marks & 3.43 & 1.00 & 15 & Moderate \\
\hline
\end{tabular}

to study individuals on the total score of the excitement style scale, where the significance values for " $\mathrm{f}$ " was greater than (0.05) for each case.

The researchers attribute the above results to the fact that faculty members believe in the importance of these styles in increasing students' motivation towards distance learning and enhancing the communication process with teachers, enabling them to understand the educational content and obtain positive academic results. Moreover, faculty members at the university are fully aware of the importance of employing excitement styles in the educational process, as reflected by the high results in the study sample responses' analysis. All the above indicates the effectiveness of the university's training programs and continuous professional development to faculty members, especially during the Corona pandemic. This result is in line with the previous study of Abu Daf (2015) on the 
Table 4: The arithmetic means and standard deviations of the remote excitement style scale from the students' perspective according to the variables of Gender, Faculty, and program

\begin{tabular}{|c|c|c|c|c|}
\hline Gender & Faculty & Program & Arithmetic mean & Standard Deviation \\
\hline \multirow[t]{6}{*}{ Male } & Scientific & Undergraduate & 3.61 & .96 \\
\hline & & Graduate & 3.69 & .88 \\
\hline & & Total degree & 3.63 & .94 \\
\hline & Humanities & Undergraduate & 2.80 & 1.00 \\
\hline & & Graduate & 3.54 & .00 \\
\hline & & Total degree & 2.90 & .96 \\
\hline \multirow[t]{6}{*}{ Female } & Scientific & Undergraduate & 3.53 & .89 \\
\hline & & Graduate & 3.20 & 1.11 \\
\hline & & Total degree & 3.40 & .99 \\
\hline & Humanities & Undergraduate & 3.07 & 1.53 \\
\hline & & Graduate & 2.87 & 1.00 \\
\hline & & Total degree & 2.97 & 1.26 \\
\hline
\end{tabular}

Table 5: Results of MANOVA to examine the significance of differences between the arithmetic means of the excitement Styles Scale According to the different variables (gender, faculty, and program type) of the study members

\begin{tabular}{|c|c|c|c|c|c|}
\hline Source & Sum of square & Degree of freedom & Mean of squares & $F$ & Sig \\
\hline Gender & .985 & 1 & .985 & 1.017 & .314 \\
\hline College & 3.187 & 1 & 3.187 & 3.291 & .071 \\
\hline Program & .092 & 1 & .092 & .095 & .759 \\
\hline gender ${ }^{*}$ college & .029 & 1 & .029 & .029 & .864 \\
\hline gender ${ }^{*}$ program & 1.843 & 1 & 1.843 & 1.903 & .169 \\
\hline college ${ }^{*}$ program & .647 & 1 & .647 & .668 & .414 \\
\hline gender ${ }^{*}$ college ${ }^{*}$ program & .302 & 1 & .302 & .312 & .577 \\
\hline Error & 280.865 & 290 & .969 & - & - \\
\hline Total & 3809.795 & 298 & - & & - \\
\hline
\end{tabular}

positive impact of training on enhancing teachers' practice for excitement styles.

\section{Recommendations}

Considering the results, the researchers recommend the following:

- Educating faculty members about the various electronic programs and applications that can be used in distance education to increase students' motivation towards learning and building the diverse knowledge and skills related to that.

- Providing various types of logistic and technical support by higher education institutions to faculty members and providing them with open educational resources to ensure effectiveness in university education, whether in an integrated or remote form.

- Involving university teachers in specific courses about the employment of technology and distance education platforms, introducing all the advantages and training them to employ it in remote university education.

\section{Conclusion}

Practicing a variety of excitement styles during the learning process helps to motivate students and improve their ability to learn. The need for teachers to use more of these styles during distance learning is growing, such as diversifying tone of voice, using interactive body language through cameras across educational platforms, providing continuous feedback for students in each educational situation, and using interactive electronic applications both inside and outside the educational situation to ensure that students continue to learn, however, Using excitement styles during the learning process is considered challenging for teachers particularly in distance learning. Success and excellence in these styles depend on teachers' competence and their diverse teaching skills. In this article, we find that the degree to which faculty members practice excitement styles during distance learning was medium, highlighting the need for greater educational institution readiness and preparation, provision of all necessary equipment and services, and provide quality 
training programs aimed at improving teaching performance to achieve effective learning.

\section{References}

Abu Daf, M. (2015). The degree to which high school teachers practice reinforcement and excitement styles, as mentioned in the prophet Muhammad Sunnah. Journal Of The Islamic University Of Educational And Psychological Studies, 23(3), 25-52.

Al Jarrah, A., AlMufleh, M., Al Rabie'e, F., \& Gawanemeh, M. (2014). The impact of teaching using educational software in improving students' motivation to learn mathematics among second-grade students in Jordan. The Jordanian Journal Of Educational Sciences, 10(3), 261-274.

Al-Hudayris, M. (2019). The styles followed by the secondary school teacher and its relation to increasing the learner's motivation towards learning. The Arab Journal Of Scientific Publishing, 13, 65-93.

Elmahdi, I., Al-Hattami, A., \& Fawzi, H. (2018). Using Technology for Formative Assessment to Improve Students' Learning. TOJET: The Turkish Online Journal Of Educational Technology, $17(2), 182-188$.

Frenzel, A., Taxer, J., Schwab, C., \& Kuhbandner, C. (2018). Independent and joint effects of teacher excitement and motivation on student motivation and experiences: A field experiment. Motivation And Emotion, 43(2), 255-265. doi: 10.1007/s11031-018-9738-7

Ghobari, T., \& Abu Shairah, K. (2009). The degree to which general secondary school teachers practice strategies to stimulate curiosity with their students from students' perspectives in light of some variables, governorate of Irbid. Studies, Educational Sciences, 36, 398-411.

Biggs, J. B. (2001). Enhancing learning: A matter of style or approach? ,Perspectives on thinking, learning, and cognitive styles (pp.. 73-102). London:Lawrence Erlbaum Associates

Jassim, S. (2021). The degree to which Islamic education teachers practice enthusiasm and excitement styles in teaching the Holy Qur'an from their perspective in the upper elementary stage in Amman (Masters Degree). Al al-Bayt University.

Keller, M., Hoy, A., Goetz, T., \& Frenzel, A. (2015). Teacher excitement: Reviewing and Redefining a Complex Construct. Educational Psychology Review, 28(4), 743-769. doi: 10.1007/ s10648-015-9354-y

Klibanov, O., Dolder, C., Anderson, K., Kehr, H., \& Woods, J. (2018). Impact of distance learning via interactive videoconferencing on students' course performance and satisfaction. Advances In Physiology Education, 42(1), 21-25. doi: 10.1152/ advan.00113.2016

Lazarides, R., Gaspard, H., \& Dicke, A. (2019). Dynamics of classroom motivation: Teacher excitement and the development of math interest and teacher support. Learning And Instruction, 60, 126-137. doi: 10.1016/j.learninstruc.2018.01.012

Lynch, M. (2016). Excitement Equals Excellence: How Educators can Rile up Student Motivation. Retrieved 1 October 2020, from https://www.theedadvocate.org/excitement-equals-excellenceeducators-can-rile-student-motivation/

Saadeh, J. (2018). Modern Teaching Strategies. Amman: Daar al Maseera.

Sadeghi, M. (2019). A Shift from Classroom to Distance Learning: Advantages and Limitations. International Journal Of Research In English Education, 4(1), 80-88. doi: 10.29252/ijree.4.1.80

Kumar Basak, S., Wotto, M., \& Bélanger, P. (2018). E-learning, M-learning and D-learning: Conceptual definition and comparative analysis. E-Learning And Digital Media, 15(4), 191-216. doi: 10.1177/2042753018785180

UNESCO. (2002). Open and distance learning-Trends, policy and strategy considerations. Paris: FR: UNESCO. 